Etnográfica

Revista do Centro em Rede de Investigação em

Antropologia

vol. 21 (1) | 2017

Vol. 21 (1)

\title{
Experiência da pena e gestão de populações nas penitenciárias de São Paulo, Brasil
}

Punishment experience and population management in penitentiaries of São

Paulo, Brazil

\section{Rafael Godoi}

\section{(2) OpenEdition}

\section{Journals}

Edição electrónica

URL: https://journals.openedition.org/etnografica/4805

DOI: $10.4000 /$ etnografica.4805

ISSN: 2182-2891

\section{Editora}

Centro em Rede de Investigação em Antropologia

\section{Edição impressa}

Data de publição: 1 fevereiro 2017

Paginação: 27-48

ISSN: 0873-6561

\section{Refêrencia eletrónica}

Rafael Godoi, «Experiência da pena e gestão de populações nas penitenciárias de São Paulo, Brasil», Etnográfica [Online], vol. 21 (1) | 2017, posto online no dia 11 março 2017, consultado o 11 fevereiro 2022. URL: http://journals.openedition.org/etnografica/4805 ; DOl: https://doi.org/10.4000/ etnografica. 4805

\section{(c) (;) (9)}

Etnográfica is licensed under a Creative Commons Attribution-NonCommercial 4.0 International License. 


\section{Experiência da pena e gestão de populações nas penitenciárias de São Paulo, Brasil}

\section{Rafael Godoi}

A partir de observação participante no interior de algumas penitenciárias de São Paulo, na qualidade de voluntário da Igreja Católica, exploro certas dimensões estruturantes do funcionamento atual e cotidiano dessas prisões, especialmente no que se refere à execução penal e às sanções disciplinares. Recorro a algumas sugestões foucaultianas sobre a governamentalidade para identificar particulares dinâmicas de gestão de uma cada vez mais expansiva população carcerária. Finalmente, discuto como esses achados de pesquisa podem contribuir para o entendimento do encarceramento em massa contemporâneo, bem como do fenômeno das facções prisionais brasileiras.

PALAVRAS-CHAVE: prisão, justiça, estado, governamentalidade, São Paulo.

Punishment experience and population management in penitentiaries of São Paulo, Brazil - In this paper, I explore some structural dimensions of the daily functioning of São Paulo penitentiary system, especially related to juridical and disciplinary issues. The field work focused on some penitentiaries in São Paulo's metropolitan region - where I entered as a catholic volunteer. I turn to some suggestions on foucauldian governmentality to identify certain management dynamics of an increasingly expansive prison population. Finally, I discuss how these research findings can contribute to the understanding of contemporary mass incarceration as well as the phenomenon of prison factions in Brazil.

KEYWORDS: prison, justice, state, governmentality, São Paulo.

GODOI, Rafael (rafael.godoi@usp.br) - Departamento de Sociologia da Universidade de São Paulo, Brasil. 


\section{INTRODUÇÃO}

Transformações importantes no funcionamento do sistema de justiça penal, em diversos países, remontando, em linhas gerais, ao último quarto do século $\mathrm{XX}$, foram e ainda são objeto de um vigoroso debate nas ciências sociais (cf. Canêdo e Fonseca 2012). ${ }^{1}$

Não obstante divergências nas análises, ênfases e conclusões, é recorrente a abordagem de um determinado conjunto de elementos que indicaria essa grande transformação. $\mathrm{O}$ aumento exponencial da população carcerária e das taxas de encarceramento, mais ou menos concomitante em diferentes países, constitui uma das evidências empíricas de maior relevo e aponta para a importância, a profundidade e a amplitude das mudanças que resultaram nas atuais formas de controle e punição (Garland 2001).

A redefinição da função social da prisão é um ponto comum em diferentes análises. Existe relativo consenso quanto ao fato de a prisão ter sido esvaziada de seus objetivos ressocializadores, passando a funcionar como mero dispositivo de contenção e incapacitação de amplas camadas populacionais marginalizadas (Garland 2005: 41-42). A prisão passa a se figurar como depósito de um excedente populacional que não para de crescer em tempos de globalização e de ajustes neoliberais.

Minha proposta neste trabalho é tomar a prisão-depósito como problema para a investigação empírica, a partir de algumas observações que pretendem evitar uma aceitação por demais irrefletida dessa tese. Em primeiro lugar, ressaltaria a necessidade de não se tomar por análise crítica o que na verdade se constitui como o novo conteúdo programático dos sistemas punitivos contemporâneos. Operadores, apologistas e estrategistas do endurecimento penal são os primeiros a afirmar que a prisão funciona como mecanismo de contenção e incapacitação de criminosos (Feeley e Simon 2012: 28). A segunda observação decorre da primeira: é preciso problematizar a eficácia de tal programação. Muitas vezes, os estudiosos se limitam a constatar a nova função incapacitante da prisão para, em seguida, empreender maiores esforços na investigação de suas causas históricas e culturais (Simon 2001), dos sistemas de pensamento que lhe dão sustentação (O’Malley e Hutchinson 2007) ou dos mecanismos de poder que a integram numa estratégia de governo mais ampla (Rose 2000). A prisão contemporânea aparece então como algo que tem uma função social bastante clara, mas cujo funcionamento não inspiraria maior interesse - como se a nova prisão-depósito, simplesmente, armazenasse, anulasse e incapacitasse, e nela nada mais pudesse acontecer.

l Este artigo é baseado em pesquisa realizada com recursos da Fundação de Amparo à Pesquisa do Estado de São Paulo (FAPESP). 
Ao enfatizar a necessidade de problematização da eficácia do programa neutralizador, evoco algumas das maiores contribuições de Foucault (1999) para a análise e a crítica de nossos sistemas punitivos: o cuidado de não tomar a prisão como dispositivo meramente repressivo, nem o poder como relação meramente negativa. Não é porque a prisão já não se representa como o aparelho disciplinar que Foucault analisou que deixa de fazer sentido o estudo de sua mecânica de funcionamento e a prospecção de suas produtividades. Ademais, se Foucault (1999: 226-227) coloca como questão estratégica a indagação sobre a eficácia que subjaz as reiteradas denúncias de fracasso da instituição, talvez, no momento atual, seja o caso de propor, inversamente, questionamentos sobre os fracassos que se produzem sob as reiteradas proclamações de que a prisão funciona. No estado de São Paulo, a emergência das facções prisionais, especialmente do Primeiro Comando da Capital (PCC), e a extensão de suas atividades para muito além do perímetro prisional (Adorno e Salla 2007; Telles 2010; Biondi 2010; Feltran 201 1; Dias 2013) são fatores que colocam na ordem do dia a indagação sobre o funcionamento atual de uma prisão que se pretende meramente neutralizadora.

Proponho neste trabalho, portanto, o seguinte percurso: partir da função prisão-depósito para uma exploração do funcionamento da prisão "massificada". Isto é, não se trata de elucidar, mais uma vez, qual a função geral da prisão contemporânea, mas de questionar como ela vem funcionando, num contexto específico e estratégico como São Paulo. Para tanto, recorro a algumas sugestões foucaultianas sobre a governamentalidade e o neoliberalismo (Foucault 2008a, 2008b). Técnicas atuariais, modos de intervenção ambiental, formas de responsabilização dos sujeitos, estratégias de condução e capitalização de suas escolhas e ações, entre outros elementos característicos da governamentalidade neoliberal, podem, com proveito, iluminar as linhas gerais que articulam os mecanismos mais amplos de segurança e justiça - onde a prisão figura como um elemento entre outros -, servindo também de referência para conferir inteligibilidade a emergentes dinâmicas de gestão do próprio espaço penitenciário (Garland 1997).

Esses temas serão aqui trabalhados desde uma perspectiva etnográfica, a partir da observação participante nas atividades de um grupo da Pastoral Carcerária - organização ligada à Igreja Católica - no interior de algumas penitenciárias de São Paulo. As técnicas de gestão da população carcerária paulista são, portanto, prospectadas a partir de algumas experiências de campo, nas quais me parece ter sido possível acessar dinâmicas estruturantes da própria experiência da pena (Kaminski e Kokoreff 2004: l l) que é imposta, se não a todos, a um número significativo dos presos condenados pelo estado de São Paulo. 


\section{UMA VISITA PASTORAL}

"A pastoral, a pastoral..." é o grito que emana do outro lado da porta de aço. Eu e Fátima ${ }^{2}$ estamos na "gaiola" que dá acesso a um dos "raios" de uma penitenciária do estado de São Paulo. Um agente de segurança penitenciária (ASP) foi avisar a respeito de nossa chegada, outros três estão ali, trocamos algumas palavras de cordialidade. Minha atenção se volta para o que se pode ver através de uma pequena janela: o futebol é interrompido imediatamente, os presos se agitam, correm para as suas celas, vestem camisetas, alguns penduram terços no pescoço. A um sinal dos presos, o ASP que estava lá dentro nos convida a entrar. Passamos pela porta de aço e adentramos em outra "gaiola", menor, dentro do "raio". Três grades nos separam de um grupo de presos que já vai se aglomerando, alguns sorrindo, outros curiosos. Quando se fecha a porta às nossas costas, o ASP abre outra, passamos; ele nos tranca dentro do "raio" e sai.

Cumprimento com um aperto de mão todos os que se aproximam, os "setores de judiciária”, presos responsáveis pela nossa recepção, e os demais, conhecidos ou não. Uma enorme quantidade de gente passa a caminhar em círculo pelo pátio central, em pares ou pequenos grupos, aproveitando do sol. Muitos continuam suas atividades, observando-nos de longe, sentados na porta de uma cela, jogando baralho, costurando bolas. Num canto do pátio, uma grande mesa de madeira vai sendo disposta a fim de centralizar o nosso atendimento. Antes de iniciá-lo, Fátima diz que quer fazer uma oração. Os "setores" então gritam "A oração, oração..." e, com o grupo que já se forma ao nosso redor, caminhamos para o pátio, que vai se abrindo. Rapidamente, um enorme círculo se forma, nem todos se aproximam, alguns ficam só olhando, mas um silêncio se faz. Quando todos no círculo já estão de mãos dadas, Fátima cumprimenta: "Bom dia, povo de Deus!" A resposta vem grave e uníssona: "Bom dia, Dona Fátima!" Ela então explica rapidamente que trouxe os extratos pedidos na última semana, que só levará mais pedidos daqueles que não conseguiram fazê-lo na última vez, e que estes só poderão ser entregues depois de quinze dias, já que na semana seguinte não os visitaremos. Proclama então algumas breves intenções para a família e a saúde, e inicia o Pai Nosso ecumênico. Os católicos emendam a Ave Maria, os evangélicos calam. Uma salva de palmas encerra o momento da oração.

Caminhamos em direção à mesa, enquanto somos abordados por vários presos e suas questões: "O que precisa para pedir o extrato? Número de matrícula serve?" Quando nos aproximamos, uma longa fila já está formada. Fátima procura em sua pesada sacola o maço de extratos correspondente ao "raio" em que estamos e o entrega nas mãos do "setor", que repassa a outro que o leva para a sala da "judiciária", a fim de organizar a distribuição - um volume grande 
de presos se dirige para lá. Fátima também retira da sacola um maço de papéis em branco e uma caneta, o "setor de judiciária" pede então que um preso que estava ali do lado se encarregue de fazer a relação. Fátima reitera que é só para aqueles que não pediram na última visita. Do outro lado da mesa, ele começa a anotar no papel os dados daqueles que estavam em fila. Dá-se início, então, aos atendimentos individuais.

Eu e Fátima ficamos de pé, perto da mesa, cada um rodeado por presos ansiosos por conversar e tirar dúvidas. Além das questões pontuais sobre as informações necessárias para a realização do pedido do extrato, todo um universo de questões processuais nos é apresentado. O diálogo se inicia com um aperto de mãos, o preso então explica sua situação. Muitos têm uma condenação de X anos, já cumpriram Y da pena, tendo, portanto, lapso para progredirem de regime ou mesmo para serem soltos; no entanto, estão lá ainda, sem informação sobre o andamento de seus "benefícios". Outros, ou têm um advogado particular que deixou de atuar em seu caso; ou já progrediram para o regime semiaberto e ainda não foram transferidos; ou apelaram da condenação e não têm informação alguma sobre esse processo; ou acabam de ser condenados num outro processo e não sabem como vai ficar a pena. Questões pessoais de diversas ordens também emergem: a necessidade de óculos, de medicamentos, de notícias da família; protocolos para contrair matrimônio, para registrar um filho. Fátima tem praticamente todas as respostas, anota nomes e problemas em sua agenda; o círculo ao seu redor é bem maior que ao meu. Eu respondo o que posso, anoto alguns nomes e dúvidas.

Conforme os extratos vão sendo distribuídos na sala da "judiciária”, muitos vêm nos procurar para interpretá-los, uma vez que as informações neles dispostas são bastante cifradas, não permitindo observar muito mais que as datas em que o processo foi movimentado e onde ele atualmente se encontra. Tendo somente por base o extrato, é praticamente impossível ter conhecimento acerca da natureza dos pedidos e dos encaminhamentos que vão sendo dados. Por mais frustrante que seja a desinformação imposta pelo papel, o registro de uma movimentação recente é suficiente para amenizar a angústia e os ânimos mais exaltados.

Fátima olha para o relógio: estamos atrasados, há muito ainda a visitar. Desculpando-se, interrompe os atendimentos e recolhe a relação de pedidos de extratos. Um calhamaço, dezenas e dezenas de nomes e números. Aqueles mais atrasados tentam incluir, na última hora, o nome na lista; Fátima resiste e cede, resiste e cede; anotações de última hora também são feitas em sua agenda - uma pomada, um telefone de familiar, um número de processo de apelação tudo enquanto o "setor de judiciária" chama na "gaiola": "Senhor, atenção aqui para o raio..." Depois de Fátima ter guardado a relação, enquanto esperamos a reação dos funcionários, presos ainda se aproximam pedindo que levemos bilhetes com seu nome e número de execução, também com indicações do 
tempo de pena imposta e cumprida, ao que cedemos conforme a insistência de cada um. Um ASP entra na "gaiola" do "raio" e abre a porta para nossa saída. Vamos nos despedindo e com promessas de voltar. Do outro lado da porta de aço, os outros ASP recebem um preso vestido de branco, empurrando um carrinho repleto de tinas com arroz, feijão, carne e banana, comida que naquela hora seria distribuída naquela mesma mesa em que há pouco atendíamos. Ele cumprimenta "Dona Fátima", pede ajuda para ver como anda o seu processo e diz que na sua cela tem uma petição de liberdade condicional para ela protocolar no Fórum.

\section{UM MODO DE GOVERNO À DISTÂNCIA}

Extratos da Vara de Execuções Criminais (VEC) e de apelação são os mais pedidos e distribuídos em qualquer "raio" que eu, Fátima e outros agentes pastorais visitamos. Do universo de problemas que se apresentam nas penitenciárias paulistas, não temos nenhuma predileção pelas questões processuais, mas elas se impõem, incontornáveis, quando dialogamos com os presos, demonstrando abertura e interesse por suas maiores angústias. A apreciação desses documentos e de seus efeitos no "raio" de penitenciária possibilita jogar luz sobre algumas dimensões estruturantes do governo e da experiência da punição em São Paulo.

O extrato da VEC é um documento que informa sobre os encaminhamentos de pedidos de "benefício" - geralmente progressão de regime ou liberdade condicional - no processo de execução penal. É emitido pelo Tribunal de Justiça do Estado de São Paulo via Internet e se compõe de quatro colunas com diferentes tipos de dados. Nas sete linhas aparecem as sete últimas movimentações no processo de execução, em ordem cronológica decrescente. A primeira coluna é a mais legível. A sucessão de datas informa se o processo está parado ou em andamento, o ritmo das movimentações processuais, o intervalo entre elas, e o momento preciso em que foram realizadas. A leitura dessas datas depende de outras referências temporais, que os presos, em geral, dominam: o dia da prisão, a duração da pena imposta, os lapsos de tempo legalmente determinados para progressão de regime segundo as diferentes condenações. $\mathrm{Na}$ segunda coluna, registros como "Autos no Ministério Público", "Autos na Defensoria Pública", "Autos Remetidos à Comarca", "Autos Recebidos da Comarca", "Autos no Arquivo" são referências espaciais que indicam onde está se passando algo com o processo. Sendo jurisdicionalizada a execução da pena - constituída, portanto, de ações e transações entre os diversos agentes que conformam o sistema de justiça (Teixeira 2009) -, as informações dessa coluna possibilitam identificar quem é o responsável por cada movimentação em curso - se o promotor, o defensor ou o juiz - e, relacionando-as com as da primeira coluna, quanto tempo cada um desses agentes leva para concluir 
seus procedimentos. Entretanto, o número limitado de sete movimentações apresentadas no extrato impossibilita a reconstituição do percurso geral de um "benefício". Assim, o andamento processual mais se apresenta como um incessante ir e vir, sem início, sem fim, imprevisível, ilegível. Ademais, no extrato da VEC jamais figurará a decisão judicial proferida - o que eleva a ilegibilidade do documento ao paroxismo. Não obstante, com o extrato da VEC em mãos, o preso continuamente redimensiona os aspectos quantitativos e qualitativos da pena que sofre: seu tempo de duração e regime de cumprimento. De um lado, especula sobre a data provável de sua saída, se ela tende a se aproximar do cumprimento integral da pena ou se já se anuncia para o próximo período. De outro, questiona a justeza de sua própria condição: se a pena que lhe vem sendo imposta corresponde ou não aos seus direitos legalmente estabelecidos. Feitas e refeitas a cada extrato, a cada dia, verdadeiros focos de angústias e incertezas, essas estimativas e considerações carecem de precisão, em grande medida, devido à quase total ilegibilidade do restante da tabela, que, por sua vez, prolonga uma opacidade que é própria do sistema de justiça. Se não deixa de ser surpreendente o fato de existir tamanha demanda por um documento tão lacunar, deve-se ter em mente que, nas penitenciárias paulistas, são por demais escassos os canais de circulação de informações processuais.

Os extratos de apelação, embora igualmente demandados e também acessíveis via Internet; são distribuídos em menor número que os da VEC. Geralmente os presos, no "raio", não dispõem de informações precisas para a sua busca. Apenas com o nome completo, o número do processo de execução e da matrícula no sistema prisional - esses os dados de que os presos, em geral, dispõem - é quase sempre impossível emitir o extrato de apelação requerido. Nesse documento figuram informações acerca do processo de apelação à condenação proferida em primeira instância. Trata-se de outro processo, diferente da execução penal, mas que também se vincula ao preso e a seu destino. O direito de apelação é amplamente consolidado nos sistemas jurídicos modernos; visa proteger acusados e acusadores de possíveis negligências ou equívocos numa primeira decisão judicial. Geralmente, o processo de apelação se inicia logo após o primeiro julgamento, quando se dá a conhecer a pena imposta, considerada inapropriada pelo defensor ou pelo promotor - pelo excesso ou pela falta de rigor. Para além de toda a justificação própria da doutrina jurídica, a existência de processos de apelação nos gabinetes do sistema de justiça e o interesse por seus extratos nos "raios" do sistema penitenciário indicam que a pena, mesmo quando já estabelecida, pode ser vivida como algo potencialmente mutável, para mais ou para menos, continuando mesmo enquanto é aplicada, em alguma medida, ainda indefinida.

Diferentemente do extrato da VEC, no de apelação, a consulta às movimentações pode recuar até o cadastramento do processo, possibilitando uma visão geral sobre o ir e vir processual. Na coluna "Movimento", sucedem-se ao 
cadastro múltiplas remessas, distribuições, recebimentos, pareceres e publicações que envolvem arquivistas, cartorários, procuradores, defensores e magistrados. Após o julgamento, são necessárias outras remessas e publicações para que a nova decisão proferida incida no processo de execução, redefinindo (ou não) condições, lapsos e direitos no interior do sistema prisional. Quando existe uma decisão judicial, sua natureza é telegraficamente informada no extrato, com meras indicações do acolhimento total ou parcial, ou da refutação da demanda do apelante.

Os extratos da VEC e de apelação distribuídos pelos agentes pastorais são importantes e muito demandados no "raio" de penitenciária, porque permitem que o preso estabeleça um mínimo contato com o andamento, nos circuitos do sistema de justiça, de dois dos mais importantes processos que definem seu destino. No entanto, trata-se de um contato ambivalente, que pode amenizar ou agravar os ânimos: saber que seu processo de apelação está estagnado há anos num arquivo, ou que o "benefício" está parado há meses na mesa do juiz, enquanto se aproxima a próxima saída temporária ou outro lapso está para ser cumprido, conforma circunstâncias que intensificam a angústia vivida na prisão. Por outro lado, saber que o pedido de "benefício" se movimentou diversas vezes num mesmo mês pode alimentar esperanças de uma antecipação da liberdade. De um modo ou de outro, a leitura dos extratos traz à tona um tipo particular de sofrimento experimentado na prisão, referente ao próprio regime de processamento das condenações e dos condenados pelo sistema de justiça.

É sempre possível problematizar a opacidade do sistema de justiça, a ilegibilidade de suas operações, também as experiências e sofrimentos que engendram, analisando as diversas instituições, seus aspectos organizacionais, suas disfunções logísticas. Desde esse ponto de vista, é possível discutir a precariedade das estruturas voltadas à defesa jurídica gratuita; o desconhecimento, por parte de promotores e juízes, das condições reais de encarceramento; ou a inadequação dos recursos técnicos e administrativos das varas. A análise, no entanto, não ultrapassaria os limites do registro negativo. As situações e experiências que acabo de descrever apareceriam então como decorrência da falta - de eficiência, de recursos, de procedimentos, no limite, de Estado. No entanto, não é porque juízes e promotores só muito raramente visitam unidades penitenciárias, não é porque inexiste um número adequado de defensores públicos exclusivamente voltados para a execução penal, que o sistema de justiça deixa de fazer o seu trabalho no que diz respeito ao regime de processamento penitenciário. Ele age à distância, por meio do processo e das várias documentações que nele confluem. Concluir que a experiência de uma pena ilegível e indefinida resultaria da ausência ou ineficiência do Estado na prisão só seria possível se se mantivesse irrefletido o pressuposto de que o perímetro institucional bem delimita uma unidade de análise (Cunha 2004). Ou seja, seria o mesmo que negligenciar tanto as múltiplas conexões que ligam uma unidade prisional a 
outros territórios, quanto a profusão de documentos que por essas vias circulam, permeando a vida e definindo o destino dos presos.

$\mathrm{Na}$ prisão contemporânea, que abdicou de seus ideais ressocializadores, que incapacita um número cada vez maior de pessoas, o gerenciamento meramente burocrático da população prisional assume uma renovada importância estratégica. Os extratos descritos colocam presos e agentes pastorais diante das expressões mais cotidianas e triviais dos expedientes de gestão de maior peso na operacionalização do fluxo de condenados pelo sistema penitenciário. Transações documentais têm, com efeito, o poder de determinar a duração e as condições do período de reclusão, não importando se se efetuam em outras territorialidades. Se os prazos procedimentais são sistematicamente extrapolados, se as intervenções dos diversos operadores do direito são por demais protocolares e se a desorganização logística é a marca da relação entre as diferentes agências do sistema de justiça, o particular regime de processamento que viabiliza o funcionamento do sistema penitenciário não deve ser apenas visto como obviamente incompatível com o código legal, mas também, sobretudo, como a compatibilização prática, empírica, entre o imperativo securitário da contenção incapacitante e as exigências legais de um sistema que se caracteriza pela progressividade das penas e pela jurisdicionalização da execução.

Esse regime de processamento pode ser pensado como uma forma particular de governo à distância (Miller e Rose 1990; Rose 2000; Rose, O’Malley e Valverde 2006) que opera por meio de tecnologias de escrita (Latour 1986; Das 2007; Gupta 2012), onde a interação direta entre presos e agentes estatais é reduzida ao mínimo possível. Cadastros, peças, remessas, juntadas, distribuições, vistas, publicações são apenas alguns exemplos das modalidades de ação estatal que prevalecem nesse circuito. Escrever, compilar, transportar e ler uma infinidade de registros é um tipo de ação cotidiana das forças estatais, com efeitos próprios. A composição e a manipulação dos diferentes processos não são meros expedientes burocráticos, colaterais, secundários em relação a outro tipo de ação que seria mais real - seja o mero confinamento, seja algum tipo de tratamento penitenciário. Foucault já chamava a atenção para a centralidade dos registros escritos - das "técnicas documentárias" (1999: 157) - na operacionalização e desenvolvimento das disciplinas. O vínculo estratégico entre formas de conhecer o indivíduo e de exercer poder sobre o corpo parece funcionar agora de outro modo - em escala, por agregado. Se nas disciplinas, através de sucessivos exames, as autoridades fazem proliferar um conhecimento sobre as aptidões e as tendências subjetivas de cada um, a fim de classificar e prognosticar o tratamento específico ao indivíduo, nesse particular governo judiciário, os registros do processo operam por redução, por extração (Latour 1986: 17) dos elementos considerados centrais para fundamentar a decisão sobre direitos adquiridos e sobre a necessidade (ou não) de dar continuidade à reclusão do maior número de pessoas, no menor tempo possível. 
O conjunto de documentos escritos que constitui um processo duplica a existência do preso num outro circuito, ao mesmo tempo em que concretiza o Estado e sua ação sobre a população carcerária, por outros meios que não a muralha. Se no "raio" de penitenciária prevalece a indistinção das penas, a mistura dos sujeitos e o tratamento uniforme, o processo opera as segmentações, fixando as condenações e lapsos a cumprir, diferenciando o tratamento para primários e reincidentes, hediondos e comuns. É pela materialidade e pelo fluxo dos papéis que se condiciona o fluxo dos corpos e se assinala o destino de todos e de cada um. Nos gabinetes do sistema de justiça, os processos - não diretamente os presos - são avaliados, encaminhados e chancelados, e esse fluir impacta, conforma e individualiza a experiência que cada um terá na prisão. O gabinete do juiz é como um centro de comando - de avaliação, cálculo e intervenção (Miller e Rose 1990: 7) - a partir do qual é possível que um único agente, baseado num conjunto de papéis, decida sobre a vida e o destino de milhares de pessoas. Entretanto, indicar a centralidade do sistema de justiça no funcionamento do sistema penitenciário não é o mesmo que proclamar sua ascendência absoluta. Não há uma relação de dominação unívoca dos agentes do sistema de justiça sobre os funcionários da prisão, nem dos letrados da burocracia estatal sobre uma população (presa) majoritariamente iletrada. Nessa particular tecnologia de governo não só há espaço para a ação fora dos gabinetes do judiciário, como essa ação é continuamente incitada para o bom funcionamento do sistema. A abordagem dos processos de sindicância permitirá interpelar as práticas próprias da administração prisional que incidem de modo determinante nesse regime de processamento. A apreciação dos modos pelos quais os presos se mobilizam para interferir na deriva processual, por sua vez, mostrará como eles não são meros objetos passivos dessa particular forma de governo à distância.

\section{OUTRA VISITA PASTORAL}

A ala do "castigo" é um corredor estreito de odor pesado, com celas dispostas do lado esquerdo numa sequência de portas de aço e suas pequenas portinholas, de onde se projetam mãos e olhares ansiosos. Nem todas estão ocupadas. Um ASP nos acompanha. Fátima e eu caminhamos até o fundo do corredor, dizendo: "Bom dia pessoal, é a Pastoral Carcerária, viemos conversar com vocês". No trajeto, posso entrever os presos se vestindo para nos receber, ouço suspiros de alívio e esperança - "Dona Fátima, Dona Fátima, aqui! Por favor, aqui!" Observo melhor o espaço de uma cela vazia, o "pote": uma pequena janela envidraçada oposta à porta, sob a qual uma fenda na parede permite a entrada do ar; um buraco no chão, uma torneira pingando, uma caixa de concreto fazendo as vezes de cama.

Do fundo para a frente, através das portinholas, conversamos com doze fragmentos de bocas ou olhos, distribuídos em sete celas: na primeira, estavam 
dois presos acusados de serem os donos de uma porção de maconha encontrada na última blitz; cumpriam dez dias de castigo provisório, enquanto não se concluía a sindicância. Anotamos os contatos de seus familiares para avisarmos que não poderiam visitá-los no próximo fim de semana; ambos estavam preocupados com o gasto e o esforço inútil. Também pediram ajuda para viabilizar alguma defesa no processo de sindicância, para livrar pelo menos um deles do castigo. No segundo "pote" visitado estava um preso que foi flagrado recebendo um telefone celular do advogado, já havia cumprido dez dias de castigo provisório, passado uma semana no "raio" - aguardando a conclusão da sindicância - e estava, naquele momento, no penúltimo dos vinte dias de pena pela falta. Na terceira cela, apenas um dos dois presos quis conversar conosco; não estava de castigo, mas em regime de observação, tendo chegado há pouco na unidade, vindo de uma penitenciária no interior do estado. Pediu que avisássemos seus familiares do novo endereço o mais rápido possível, para que não viajassem inutilmente no próximo fim de semana. Na quarta cela, conversamos com dois presos recapturados, um depois de ano e meio na rua, outro depois de alguns dias. Ambos não retornaram à unidade depois de uma saída temporária. $\mathrm{O}$ primeiro contou que, em liberdade, trocou de namorada e teve um filho; pediu-nos ajuda para recompor seu rol de visitas. $\mathrm{O}$ segundo pediu um extrato de apelação. $\mathrm{Na}$ quinta cela, também um preso recapturado e um que voltou com um dia de atraso da última saída temporária; este disse que precisou desse dia para viabilizar um abrigo para os filhos, que estavam morando na rua com a mãe viciada em crack. Estava bastante revoltado, disse que se soubesse que teria o mesmo tratamento dispensado aos recapturados, jamais teria voltado "com as próprias pernas". No sexto "pote" estava um preso sozinho, mais velho e conhecido de Fátima. Ela se surpreendeu ao reconhecê-lo: "Você aqui?" Ele, visivelmente constrangido, tentou se explicar: na última blitz, encontraram o controle remoto da televisão nas suas coisas; controle remoto é proibido, ele bem sabia, mas a preguiça de levantar toda vez para trocar de canais, desafortunadamente, tinha sido mais forte. Fátima se preocupou com o andamento de seu processo: "uma sindicância bem agora que o regime semiaberto parece que finalmente vai sair?" Ele tranquilizou-a, disse que o diretor de disciplina lhe garantiu que não abririam sindicância, que cumpriria um castigo de uma semana, mas que não seria registrado, por ser ele um preso antigo e que não dá problema. Na última cela de castigo visitada, estavam dois presos acusados de desacato a funcionário. Um não quis muita conversa conosco, apenas pediu um terço que não tínhamos para lhe dar. O outro falou mais, estava inconformado, falava alto a fim de que o ASP que nos acompanhava ouvisse, dizia não ter desacatado ninguém, que o acusaram por perseguição, que no processo de sindicância não teve direito à defesa, que foi sua palavra contra a do funcionário. Pediu-nos ajuda para formalizar algum tipo de apelação. Ao perceber um sorriso mal disfarçado no rosto do funcionário se exaltou, colocou o braço 
inteiro para fora da portinhola, apontando o indicador para o ASP, batendo nervoso na porta de aço, proferindo ameaças: "O senhor me conhece, veja lá minha ficha, o senhor sabe que comigo não tem chance, que mais cedo ou mais tarde saio daqui e aí já viu..." Eu e Fátima tentávamos acalmá-lo, dizendo que poderíamos conversar com mais tranquilidade quando ele estivesse no "raio", ele já não nos ouvia, seguia gritando sua inocência e suas reivindicações de justiça. O ASP interrompeu a situação tirando-nos do "castigo". Disse que era bom vermos como esse preso era problemático, que ele ali não tinha mais nenhum futuro, que tomaria outra falta por novo desacato, e que, por coisas como essa, não gostavam que visitássemos aquela ala.

\section{UMA PARTICULAR GESTÃO DOS RISCOS}

O breve relato de uma visita (quase) ordinária ao espaço do "castigo" de uma unidade penitenciária visa cercar um campo de práticas e discursos que é também estruturante do governo e da experiência da punição nas prisões de São Paulo: o processo de sindicância. Trata-se de um sistema punitivo particular, que funciona no interior do sistema prisional e que interfere, em grande medida, nas condições e no tempo de cumprimento da pena. Assim como aos presos e a seus familiares, aos agentes pastorais é também vetado o acesso a informações mais aprofundadas sobre tais processos, de modo que só acessamos a dinâmica que rege a distribuição dos castigos no interior da prisão através de visitas como esta e de conversas no "raio" com presos que passaram por essa experiência.

Se os processos de execução penal ou de apelação se desenrolam fundamentalmente no âmbito do sistema de justiça, na sindicância, funcionários e gestores da prisão desempenham maior protagonismo. Mesmo sua formatação institucional é híbrida: parte estabelecida na Lei de Execuções Penais (LEP) - Lei n. ${ }^{\circ}$ 7210/84; parte a cargo de autoridades administrativas da esfera estadual - em São Paulo, a última regulamentação se deu através da Resolução n. ${ }^{\circ} 144$ da Secretaria de Administração Penitenciária (SAP), de 2010. A LEP estabelece o conjunto de faltas graves, as principais sanções, as diretrizes gerais do processo disciplinar e, desde 2003, normatiza a mais dura punição que é oficialmente admitida pelo Estado brasileiro: o Regime Disciplinar Diferenciado (RDD). O Regimento Interno Padrão das Unidades Prisionais do Estado de São Paulo detalha o conjunto de faltas leves e médias, as circunstâncias atenuantes ou agravantes, e especifica os procedimentos do processo de sindicância - as formas de instauração, instrução, audiência, relatório e decisão -, que é quase inteiramente conduzido no âmbito da própria unidade prisional (Silva 2011).

Replicando o sistema punitivo mais amplo no interior da prisão, o processo de sindicância, em tese, é também jurisdicionalizado - ou seja, dependente da 
participação de juízes, acusadores e defensores. No entanto, o registro e a apuração de infrações disciplinares, normalmente, são realizados por funcionários da administração penitenciária - os ASP e diretores - sem a participação de agentes do sistema de justiça; no mais das vezes, o julgamento é proferido pelo diretor geral da unidade, que apenas informa sua decisão ao juiz de execução, que, por sua vez, acata-a e passa a considerá-la nas apreciações de pedidos de "benefícios" que possam vir a ser feitos ulteriormente.

Em linhas gerais, imediatamente após o registro de alguma infração, o preso é transferido preventivamente para o "castigo", por um tempo máximo de dez dias. No decorrer desse período, o preso deverá ser ouvido num simples depoimento ao funcionário responsável pela sindicância. Embora esteja legalmente previsto que todo o processo de sindicância deve seguir os princípios do contraditório e da ampla defesa, os advogados da Fundação Prof. Dr. Manoel Pedro Pimentel ${ }^{3}$ (FUNAP) que trabalham na unidade pouco participam desse particular processo. Muitos presos relatam que prestaram depoimentos sem a assistência de um advogado de defesa, e que tudo o que falaram, na verdade, não teve consequência prática nenhuma, bastando a acusação do ASP para imputar-lhes a culpa. Depois desse período inicial, se o processo de sindicância não for concluído, o preso retorna para o "raio", onde aguarda a decisão final, que pode levá-lo novamente ao "pote", por mais um período de até vinte dias. A depender da decisão de diretores e funcionários, o período de "isolamento" pode se dar em dupla (ou com mais pessoas), o processo de sindicância pode nem ser aberto e o juiz pode só ficar sabendo, muito depois, de tudo o que já foi decidido.

A sindicância é o processo que, em São Paulo, mais realiza o que Foucault designa como a "soberania punitiva" (1999: 207) da administração penitenciária. Através da sindicância, o poder de determinar a qualidade e a duração das penas, os direitos adquiridos e os lapsos de progressão escapa ao judiciário, que acaba por exercer um papel secundário, de mero avalista (CNJ 2012: 18). O fluxo do processo de execução penal de um preso castigado em sindicância é totalmente alterado, em primeiro lugar, porque o período no "pote" não encerra o "castigo"; o preso volta para o "raio", mas carrega um novo lapso a ser cumprido - um tempo de reabilitação, que pode chegar a um ano em casos de falta grave. Nesse período, nenhum pedido de "benefício" poderá ser feito e o que já tramita ficará parado. Ainda, para aqueles que já estão em regime semiaberto, a sindicância pode levar à regressão de regime. Finalmente, após o cumprimento do prazo de reabilitação (sem novas faltas), o registro de sindicância em seu prontuário passa a condicionar, negativamente, as decisões do juiz a respeito da concessão de "benefícios" que o preso venha a ter direito,

3 Autarquia ligada à SAP que conta com uma equipe de cerca de 200 advogados responsáveis pela defesa de mais de $90 \%$ dos presos condenados de todo o estado. 
mesmo depois de muitos anos. Tais impactos dos processos de sindicância no desenvolvimento das penas são fontes de muita angústia e ansiedade no "raio" de penitenciária, objeto de muitas dúvidas e questionamentos nas visitas pastorais.

Se, em linhas gerais, o regime de processamento penitenciário opera como uma forma de governo à distância (Miller e Rose 1990) - alijado nos circuitos do sistema de justiça, através de mediações documentais (Latour 1986), os processos de sindicância indicam que a operacionalização desse regime não se realiza a despeito dos agentes da administração prisional, mas sim através da sua ação cotidiana, da produção contínua de situações e registros que orientarão as posições e decisões dos operadores do direito. Nas prisões contemporâneas, onde prevalecem funções de contenção e incapacitação, agentes de segurança e outros funcionários não podem ser vistos como meros guardiões de um perímetro. A ação contínua e cotidiana desses funcionários, os modos como se relacionam com os presos e como apreendem as interações dos presos entre si são determinantes para o fluir das condenações e dos condenados.

Foucault afirma que a soberania punitiva da prisão - sua "Declaração de Independência carcerária” (1999: 207) frente ao sistema jurídico que lhe dá sustentação - resulta do emprego de um multifacetado conjunto de técnicas disciplinares, que, programaticamente, visam à correção dos indivíduos condenados. É certo que, na passagem do programa de correção ao de contenção, as intervenções disciplinares recuam; o monitoramento dos corpos e das disposições subjetivas de cada um já não é tão detalhista. No entanto, as sanções disciplinares seguem fundamentais e continuam estabelecendo clivagens no conjunto de presos, retardando a saída daqueles considerados mais problemáticos. De um programa a outro, a soberania punitiva tende a mudar de mãos: dos agentes técnicos - da medicina, psiquiatria, criminologia e de outras ciências do homem - aos agentes administrativos, especialmente àqueles com funções de gestão e segurança.

Atualmente, no estado de São Paulo, o registro objetivo da falta parece interferir mais na determinação da duração efetiva e condições de cumprimento da pena que um parecer informado sobre as disposições subjetivas do preso. Embora o instituto do exame criminológico evoque a dinâmica propriamente disciplinar, sua realização não é obrigatória desde a reforma da LEP de 2003 (Almeida 2014). Ademais, mesmo quando o exame é requisitado pelo juiz, as consideraçóes dos técnicos sobre a subjetividade do preso não se sobrepõem à objetividade dos registros administrativos no processo. Quando o parecer especializado é negativo, os juízes tendem a confirmá-lo, indeferindo o pedido de benefício; quando é positivo, os juízes tendem a ignorá-lo e a também negar o benefício (Teixeira e Bordini 2004: 69). Para além de seu impacto reduzido na motivação das decisões judiciais, sua realização protocolar e burocrática torna o exame mais um trâmite documental, 
cujo principal efeito é mais prolongar o tempo de espera do que interferir decisivamente no destino do condenado. Não só o registro administrativo da falta se sobrepõe à documentação propriamente técnica - funcionando como uma espécie de marcador objetivo de risco (O’Malley 2009), evidência de periculosidade, suficiente para retardar a progressão da pena e ampliar o tempo de reclusão - como os ritos de produção e a própria materialidade da documentação técnica são indistinguíveis de outras movimentações documentais que conformam o andamento processual.

\section{UMA FORMA DE RESPONSABILIZAÇÃO}

"Aos cuidados da excelentíssima Assessora da Presidência [...]

Amparo Legal: Em conformidade e o fundamento do artigo 83, inciso XIV, sucessivamente artigo 112, ambos da Lei n. ${ }^{\circ}$ 7.210/84 (Lei das Execuções Penais), subsidiárias ao artigo 5. ${ }^{\circ}$ XxxIV, alínea (2) da Constituição Federal de 1988 (Carta Magna).

Requerente/Paciente: [Nome Sobrenome], Já devidamente qualificado nos autos da Execução Criminal em epígrafe, atualmente preso e recolhido em cumprimento de pena de reclusão em regime fechado na Penitenciária [Nome] de [Cidade]-SP, sob matrícula SAP: [AAA.BBB], vem com o devido acato e mui respeitosamente em meu favor ante a presença de Vossa Excelência por intermédio desta infra-assinada representação, 'requerer' o meu pedido de Liberdade Condicional tendo em vista as razões e motivos aduzidos na forma seguinte:

I - Dos Requisitos Objetivos

Condenado com o incurso a uma pena de reclusão totalizada em 5 anos e 6 meses, por infração do artigo 155, 155 [sic] do Código Penal Brasileiro (CP). Dos quais até a presente data já estou cumprindo ininterruptamente $[N]$ anos e $[N]$ meses em regime fechado, onde, desta forma preencho o requisito objetivo conforme estipula o artigo 112 da Lei de Execuções Penais (LEP). [ ...]

\section{II - Do Requisito Subjetivo}

No que tange a esta situação o requerente preenche o requisito subjetivo sempre com 'bom' comportamento carcerário, trabalhando e respeitando funcionário e seus companheiros de infortúnio, seguindo os conformes do artigo 40 da Lei de Execuções Penais n. ${ }^{\circ}$ 7.210/84.

III - Do Pedido

Desta forma conforme todo exposto e face ao perfil apresentado não se pode negar o deferimento do meu pedido de Liberdade Condicional".

Estes trechos foram literalmente transcritos de uma carta escrita à mão, em folha de papel almaço, com canetas azul e vermelha, que enviei por correio ao 
Supremo Tribunal Federal (STF), a pedido de um preso. Sua forma, estrutura e conteúdo não diferem muito de vários documentos que cotidianamente recolhemos nas visitas pastorais para serem protocolados em Varas de Execução Penal ou enviados, por correio, a diferentes instituições - do Tribunal de Justiça do Estado de São Paulo à Presidência da República.

A gestão da população penitenciária se dá, em linhas gerais, através da mediação dos processos, das transações documentais nos circuitos do sistema de justiça, das quais os tão demandados extratos da VEC e de apelação dão notícias. Embora se constitua como uma gestão à distância, por meio do fluxo dos processos, a forma como a conduta dos presos no interior da prisão é apreendida pode determinar, em grande medida, o desenrolar das penas. Os processos de sindicância - operacionalizados soberanamente pelos agentes da administração penitenciária - constituem a ferramenta mais generalizada para assinalar indivíduos e grupos de risco entre a população prisional, para os quais as penas serão, invariavelmente, ainda mais duras e longas. No entanto, há também todo um conjunto de práticas e saberes que os presos mobilizam cotidianamente no sentido de abreviar a permanência na prisão e melhorar as condições de cumprimento de pena. A carta parcialmente supratranscrita é um exemplo desse tipo de iniciativa.

No sentido de fazer andar a execução, acelerar seus trâmites, agilizar as movimentações processuais, os presos precisam mobilizar continuamente ações e relações, tanto dentro, quanto fora dos muros. Essa mobilização - que a carta expressa - não se prescreve na lei, mas replica suas formalidades e se realiza, quase sempre, por vias informais - por intermédio de familiares, amigos e agentes pastorais. Para compreender todo esse esforço é preciso levar em conta um fator determinante no funcionamento do sistema de justiça: qualquer movimentação processual em matéria de execução penal é disparada, via de regra, por provocação. Segundo os juízes do Conselho Nacional de Justiça (CNJ), que, no âmbito de um mutirão carcerário, no segundo semestre de 2011 , inspecionaram todas as unidades prisionais do estado de São Paulo e apreciaram 76.098 processos, é manifesta a "inexistência de uma organização cartorária nas Varas de Execução no Estado, de forma que possibilite o controle das fases e das movimentações processuais [de modo que] o processo de execução, praticamente, só é movimentado quando há pedido expresso da parte interessada" (CNJ 2012: 8). Portanto, o regime institucional de processamento de pessoas, no sistema penitenciário de São Paulo, depende, em grande medida, da agência dos presos, de seus familiares e/ou defensores para que possa se desenrolar.

Não obstante a ilegibilidade característica do processamento penitenciário, o preso é quem mais se interessa e sabe sobre seu processo e direitos adquiridos. O acompanhamento das movimentações processuais, através dos extratos, não só permite ao preso vislumbrar o ritmo das transações que, à distância, 
definem seu destino, como também o mantém atualizado sobre o que poderia ou deveria ser feito em sua causa. O esforço cotidiano para saber do processo se complementa com o de promover o seu andamento. Nas visitas pastorais, é comum entrarmos na unidade com uma porção de extratos e sairmos com uma porção de documentos escritos à mão, para enviarmos pelo correio ou protocolarmos diretamente no Fórum.

Os requerimentos mais frequentes são precisamente os de progressão de regime e liberdade condicional. A precariedade do suporte material contrasta com a linguagem formal e a polidez no tratamento. Muitas vezes, os manuscritos seguem modelos que circulam nos "raios", de modo que os presos alteram somente dados pessoais e algumas passagens específicas que qualificam cada situação. Em muitos "raios", existe ainda a figura do "recursista", preso versado na produção dessas petições, o qual atua em causa própria, mas também presta seus serviços a "colegas de infortúnio", por solidariedade ou alguma remuneração. Alguns são reconhecidos como melhores que muitos advogados, públicos ou particulares. Embora não haja garantias para a eficácia do procedimento, é certo que muitos presos atribuem a esses documentos alguma melhoria ou avanço processual que experimentaram depois do seu envio.

A proliferação de documentos - sua iteratividade - é a paradoxal contrapartida de um regime de gestão calcado na ilegibilidade (Das 2007: 168). A circulação de modelos, o labor do "recursista", a redação e o envio desses manuscritos conformam todo um universo de práticas que, mesmo num embate agonístico contra as forças estatais, acaba por reproduzir suas formas e duplicar sua linguagem. Ao operacionalizar formas de gestão por meio de tecnologias de escrita, as agências estatais também instauram a possibilidade permanente - para aqueles que são assim governados - da ação por meio de falsificações, adulterações e outras performances miméticas (Das 2007: 163; Gupta 2012: 141-144, 226-231). Agentes pastorais, presos, seus amigos e familiares mobilizam técnicas de escrita, mimetizam os procedimentos que vigoram no sistema de justiça, para acionar fluxos documentais e incidir no desenrolar da pena. Operam, portanto, na mesma gramática que estrutura a gestão penitenciária, mas para viabilizar a abreviação das penas, a melhoria das condições de vida e, no limite, a saída da instituição.

Tamanha proatividade que testemunhamos e compartilhamos nas visitas pastorais evoca a crescente, contínua, mas também atomizada, responsabilização dos sujeitos que se constituem como objetos de governo (Rose 2000: 324; Garland 2005: 211 -216; O’Malley 2012: 112). No entanto, nas prisões de São Paulo, não se trata de uma injunção deliberada à participação ativa e ao empoderamento dos sujeitos na gestão de suas próprias penas, como parece acontecer em alguns laboratórios de alta tecnologia penitenciária de países do primeiro mundo - como na Escócia (Garland 1997), na Espanha (Garreaud 
2010) e no Canadá (Chantraine 2006). No estado de São Paulo, a estratégia de responsabilização se apresenta numa modulação, ao mesmo tempo, mais generalizada e particular. Generalizada porque não se restringe a alguns centros de excelência e inovação em disciplina penitenciária, mas estrutura o funcionamento do sistema como um todo. Particular porque prescinde de incentivos positivos como programas de formação, monitoramento e mecanismos formais de articulação dos diferentes sujeitos implicados nessa gestão. Nas penitenciárias paulistas, a responsabilização dos presos pelo desenrolar de suas penas é uma estratégia que funciona sem programação explícita e deliberada; é pautada pela urgência, um imperativo que decorre da necessidade de sobreviver, com a mente sã e com alguma esperança.

\section{CONSIDERAÇÕES FINAIS}

Neste trabalho, procurei expor alguns elementos da experiência da pena e das formas de gestão que incidem sobre a população de presos condenados no estado de São Paulo, tal como puderam ser apreendidos no decorrer das visitas pastorais. Tentei colocar em diálogo os dados etnográficos com algumas formulações sobre as tecnologias de saber-poder que caracterizam a governamentalidade contemporânea - especialmente, os mecanismos de governo à distância, de gestão de riscos e de responsabilização dos sujeitos. Desta experimentação emerge uma figuração do sistema de justiça penal, cujo funcionamento cotidiano se viabiliza por certas tecnologias de escrita, formas de soberania administrativa e um deflagrado regime de urgência - o que permite extrapolar a imagem estática de uma prisão-depósito.

Embora se trate de um trabalho marcadamente etnográfico e exploratório, gostaria de finalizá-lo com algumas questões para o debate sociológico acerca da grande transformação contemporânea nos regimes de controle e punição, bem como sobre as atuais querelas em torno do problema carcerário paulista, especialmente no que diz respeito à emergência e expansão do PCC.

Em primeiro lugar, no debate internacional sobre a grande transformação punitiva dos últimos anos, assim como a narrativa geral prevalecente acompanha o percurso histórico das políticas criminais dos Estados Unidos e Europa ocidental (Garland 1997, 2005), a figuração hegemônica do encarceramento em massa e suas prisões-depósitos também parece se ater às experiências dos sistemas punitivos que se situam nesse mesmo eixo geopolítico. No entanto, entre os dez países que mais encarceram no mundo - em termos absolutos e relativos -, apenas os Estados Unidos tanto seguem o roteiro do desmantelamento de um Estado de bem-estar social e concomitante edificação de um Estado penal - para ficar numa das mais consagradas versões dos fatos (Wacquant 2003) -, quanto dispõem de um sem-número de instituições de segurança máxima onde o preso parece, efetivamente, ser enterrado vivo 
(Chantraine 2006). ${ }^{4}$ Os demais países, situados no sul global, apresentam uma gama bastante diversa de estruturas organizacionais, jurídicas, políticas e sociais, bem como de percursos históricos que levaram a um punitivismo exacerbado. A abordagem dos mecanismos de funcionamento do maior sistema penitenciário estadual do quarto país que mais encarcera no mundo, além de válida e interessante por si mesma, visa também deslocar minimamente o eixo geopolítico que vem organizando as análises do encarceramento contemporâneo. Uma melhor compreensão da grande transformação punitiva deve passar por outras vias de problematização que contemplem as especificidades dessas realidades díspares e que, por isso mesmo, ofereçam novos elementos para se repensar as trajetórias e atuais circunstâncias dos sistemas penais nos países hegemônicos do Atlântico norte. A exemplo do que Roy (2009) sugere para os estudos urbanos, talvez seja o momento de se forjar uma nova geografia dos estudos prisionais, sem a qual corremos o risco de mal entender o que vem se passando no mundo.

Finalmente, quanto ao debate sobre a particular centralidade do PCC nas dinâmicas criminais, no sistema penitenciário e na sociabilidade das periferias urbanas de São Paulo, neste trabalho também proponho um deslocamento. No decorrer desta pesquisa, pude vislumbrar um sistema penitenciário cujo próprio funcionamento incita os presos a se mobilizarem ininterruptamente e a se articularem o quanto puderem com agentes do mundo extramuros. A dinâmica de processamento de pessoas nas prisões de São Paulo depende dessa ampla e contínua mobilização, dentro e fora das muralhas. Eis uma formulação que não só questiona o paradigma da prisão incapacitante, como conforma um novo plano de referência para situar o problema do PCC. Desde essa perspectiva, um conjunto de práticas conhecidas e atribuídas à facção ganha novos contornos e significações, que podem contribuir para uma melhor compreensão do fenômeno. Mecanismos de assistência jurídica - o pagamento de advogados particulares para membros e aliados da facção - já não aparecem como meras práticas assistenciais que visam favorecer um grupo de presos privilegiados (Dias 2013). Considerando o PCC como um coletivo, nos termos de Biondi (2010), tais práticas aparecem como reações coletivizadas às exigências que o estado de São Paulo impõe a todas e cada uma das pessoas que encarcera, nomeadamente, a exigência de o preso cuidar de saber sobre o

4 Segundo o International Centre for Prison Studies (ICPS), os dez países que mais encarceram no mundo, em maio de 2014, são - em ordem decrescente: Estados Unidos, China, Rússia, Brasil, Índia, Tailândia, México, Irã, África do Sul e Indonésia, em números absolutos. E em números relativos: Seychelles, Estados Unidos, São Cristóvão e Nevis, Anguilha (colônia britânica), Ilhas Virgens (colônia estadunidense), Barbados, Cuba, Belize, Ruanda e Rússia. Ver: < http://www.prisonstudies.org/highestto-lowest $>$. 
seu processo e fazê-lo andar e a exigência de extrair de sua rede de relações os recursos necessários para a manutenção de um horizonte factível de liberdade.

A partir desse renovado plano de referência que se esboça em minha etnografia, a figuração do PCC que emerge não é a de uma "organização criminosa" que ocupa as lacunas e vazios deixados por um Estado ausente, inoperante ou meramente (e, para alguns, sempre insuficientemente) repressor. A mobilização contínua e a articulação dos presos com agentes circulando fora das muralhas - fenômeno que o PCC expressa, mas não totaliza - são fatores fundamentais para o próprio funcionamento do sistema. É a prisão, como instanciação do Estado, que, para funcionar, incita os presos a se mobilizarem e se articularem com o outro lado dos muros. Se o PCC revela esse transbordamento da instituição, ele jamais poderá explicá-lo, porque é um de seus efeitos - talvez o mais espetacular - mas não pode ser sua causa, como sugerem Adorno e Dias (2013).

No horizonte de toda minha trajetória de pesquisa sobre a questão prisional sempre esteve presente a indagação sobre o que permite a irrupção de algo como o PCC. Agora, após anos de visitas pastorais, arrisco uma hipótese: é o próprio funcionamento intestino da prisão - em termos positivos e produtivos que se constitui como uma de suas mais fundamentais condições de possibilidade. O lugar do PCC no dispositivo carcerário paulista contemporâneo só poderá ser mais bem compreendido se forem consideradas a experiência de urgência que vigora nos "raios" das penitenciárias e as tecnologias de processamento que acabam por mobilizar uma variedade de agentes, dentro e fora das muralhas, não para subverter a prisão, mas para fazê-la funcionar. 


\section{BIBLIOGRAFIA}

ADORNO, Sérgio, e Camila DIAS, 2013, "Articulação entre o mundo interno e externo às instituições prisionais: questões para a construção de um novo paradigma no domínio da sociologia das prisões", Anais do 37. Encontro Nacional da ANPOCS. Caxambu, ANPOCS, disponível em < http://anpocs.org/index.php/papers-37-encontro/st/st28/8587-articula cao-entre-o-mundo-interno-e-externo-as-instituicoes-prisionais-questoes-para-a-construcao-de-um-novo-paradigma-no-dominio-da-sociologia-das-prisoes/file > (última consulta em janeiro de 2017).

ADORNO, Sérgio, e Fernando SALLA, 2007, "Criminalidade organizada nas prisões e os ataques do PCC”, Revista de Estudos Avançados, 21 (61): 7-29.

ALMEIDA, Francis, 2014, "Criminologia clínica", em Renato Lima, José Luiz Ratton e Rodrigo Azevedo (orgs.), Crime, Polícia e Justiça no Brasil. São Paulo, Contexto, 148-157. BIONDI, Karina, 2010, Junto e Misturado: Uma Etnografia do PCC. São Paulo, Terceiro Nome. CANÊDO, Carlos, e David FONSECA (orgs.), 2012, Ambivalência, Contradição e Volatilidade no Sistema Penal: Leituras Contemporâneas da Sociologia da Punição. Belo Horizonte, UfMG.

CHANTrAine, Gilles, 2006, "A prisão pós-disciplinar", Revista Brasileira de Ciências Criminais, 13 (62): 79-106.

CNJ - Conselho Nacional de Justiça, 2012, Relatório Geral: Mutirão Carcerário do Estado de São Paulo. Brasília, Poder Judiciário.

CUNHA, Manuela, 2004, "As organizações enquanto unidades de observação e de análise: o caso da prisão", Etnográfica, 8 (1): 151-157.

DAS, Veena, 2007, Life and Words: Violence and the Descent into the Ordinary. Berkeley, University of California.

DIAS, Camila, 2013, PCC: Hegemonia nas Prisões e Monopólio da Violência. São Paulo, Saraiva.

FEELEY, Malcom, e Jonathan SIMON, 2012, "A nova penalogia: notas sobre a emergente estratégia correcional e suas implicações", em Carlos Canêdo e David Fonseca (orgs.), Ambivalência, Contradição e Volatilidade no Sistema Penal: Leituras Contemporâneas da Sociologia da Punição. Belo Horizonte, UFMG, 19-54.

FELTRAN, Gabriel, 2011 , Fronteiras de Tensão. São Paulo, UNESP/CEM/CEBRAP.

FOUCAUlt, Michel, 1999, Vigiar e Punir: História da Violência nas Prisões. Petrópolis, Vozes.

FOUCAUlT, Michel, 2008a, Segurança, Território e População: Curso Dado no Collège de France (1977-1978). São Paulo, Martins Fontes.

FOUCAUlT, Michel, 2008b, Nascimento da Biopolítica: Curso Dado no Collège de France (1978-1979). São Paulo, Martins Fontes.

GARLAND, David, 1997, “Governmentality' and the problem of crime: Foucault, criminology, sociology", Theoretical Criminology, 1 (2): 173-214.

GARLAND, David (org.), 2001, Mass Imprisionment: Social Causes and Consequences. Londres, Sage.

GARLAND, David, 2005, La Cultura del Control: Crimen y Orden Social en la Sociedad Contemporánea. Barcelona, Gedisa.

GARREAUD, Álvaro, 2010, "Biopolítica y prisión: Umbrales de trabajo", em Dario Malventi (org.), Umbrales: Fugas de la Institución Total, entre Captura y Vida. Sevilla, Universidad Internacional de Andaluzia, 36-54.

GUPTA, Akhil, 2012, Red Tape: Bureaucracy, Structural Violence and Poverty in India. Londres, Duke University. 
KAMINSKI, Dan, e Michel KOKOREFF, 2004, Sociologie pénale: système et expérience. Ramonville Saint-Agne, Érès.

LATOUR, Bruno, 1986, "Visualization and cognition: Thinking with eyes and hands", em Henrika Kuklick e Elisabeth Long (orgs.), Knowledge and Society: Studies in the Sociology of Culture Past and Present. Greenwich, Jai, 1-40.

MILlER, Peter, e Nikolas ROSE, 1990, "Governing economic life", Economy and Society, 19 (1): 1-31.

O’MALley, Pat, 2009, Governmentality and Risk: Legal Studies Research Paper n. ${ }^{\circ}$ 09/98. Sydney, Sydney Law School.

O’MALLEY, Pat, 2012, "Punição contraditória e volátil", em Carlos Canêdo e David Fonseca (orgs.), Ambivalência, Contradição e Volatilidade no Sistema Penal: Leituras Contemporâneas da Sociologia da Punição. Belo Horizonte, UFMG, 101-128.

O'MALleY, Pat, e Steven HUTCHINSON, 2007, "Reinventing prevention: Why did 'crime prevention' develop so late?”, British Journal of Criminology, 47 (3): 373-389.

ROSE, Nikolas, 2000, “Government and control”, British Journal of Criminology, 40 (3): 321 -339 .

ROSE, Nikolas, Pat O’MALley, e Mariana VALVERde, 2006, "Governmentality”, Annual Review of Law and Social Sciences, 2: 83-104.

ROY, Ananya, 2009, “The 21 st-Century metropolis: new geographies of theory”, Regional Studies, 43 (6): 819-830.

SILVA, Anderson Castro e, 2011 , Participo que... Desvelando a Punição Intramuros. Rio de Janeiro, Publit.

SIMON, Jonathan, 2001, "Fear and loathing in late modernity: reflections on the cultural sources of mass imprisonment in the United States", em David Garland (org.), Mass Imprisionment: Social Causes and Consequences. Londres, Sage, 15-27.

TeIXeIrA, Alessandra, 2009, Prisões da Exceção: Política Penal e Penitenciária no Brasil Contemporâneo. Curitiba, Juruá.

TEIXEIRA, Alessandra, e Eliana BORDINI, 2004, "Decisões judiciais da Vara de Execuções Criminais: punindo sempre mais”, São Paulo em Perspectiva, 18 (1): 66-71.

TELlES, Vera, 2010, A Cidade nas Fronteiras do Legal e Ilegal. Belo Horizonte, Argvmentvm. WACQUANT, Löic, 2003, Punir os Pobres: A Nova Gestão da Miséria nos Estados Unidos. Rio de Janeiro, Revan. 